\title{
VALIDEZ EJEMPLAR, SENTIDO COMÚN Y UNIVERSALISMO: UM ESTUDIO SOBRE LA EJEMPLARIDAD EN KANT Y EN LA RETÓRICA ARISTOTÉLICA
}

\author{
Juan Carlos Castro Hernandez ${ }^{1}$
}

RESUMEN: Una de las nociones más controvertidas dentro de las interpretaciones contemporáneas de la Crítica de la facultad de juzgar, es la de "sentido común". Junto a éste, Kant propuso un nuevo modelo de validez normativa calificada como "ejemplar", cuyo planteamiento resulta bastante problemático. El presente artículo propone una lectura y una interpretación de este tipo de validez, a partir de la reactualización realizada por Alessandro Ferrara, y desde el horizonte de la tradición retórica, representada por Aristóteles Con ello se espera un mejor entendimiento del problema en cuestión, y al mismo tiempo, se pretende hacer mucho más comprensibles las posibilidades que Alessandro Ferrara le atribuye a esta forma de la normatividad.

Palabras Clave: Sentido común. Retórica. Universalismo. Juicio estético. Validez ejemplar.

\section{INTRODUCCIÓN}

Hasta hace pocos años la importancia filosófica del denominado sentido común, al igual que otros conceptos que le son aledaños, tales como el de juicio reflexionante, imaginación, validez ejemplar, entre otros; se enfocaron principalmente a una reactualización de la estética kantiana, ante los nuevos problemas que enfrentaba la interpretación y comprensión del arte vanguardista (DANTO, 2005, 2007; GADAMER, 2004; JAUSS 2002). De otro lado, las reflexiones realizadas desde la hermenéutica filosófica en torno a la problemática comprensión de la existencia humana, patrocinada por la hegemonía del pensamiento científico-racional, ha invocado también una recuperación de las mencionadas nociones (GADAMER, 1990, 2001).

${ }_{1}^{1}$ Profesor de Filosofía de la Facultad de Ciencias Humanas y Económicas, Universidad Nacional de Colombia, Medellín - Colombia. (D) https://orcid.org/0000-0002-9536-8304 E-mail: jccastroh@ unal.edu.co

http://dx.doi.org/10.1590/0101-3173.2019.v42n3.03.p33 
Recientemente vienen destacándose ciertas interpretaciones que enfatizan el horizonte ético-político de sus contenidos, y de los asuntos que permite ilustrar, extrapolando el contenido estético filosófico (Kant) de tales conceptos, hacía el terreno de lo político, lo sociológico y lo cultural, entre otros. ${ }^{2}$

El presente artículo tiene como objeto el análisis e interpretación de algunos lugares de la Crítica del juicio kantiana, que permitirían ponderar el verdadero alcance de un atípico modelo de "validez normativa", que la fundamentación kantiana de la estética favorece. $Y$ es que, en efecto, una de las sorpresas más significativas de la lectura de la tercera Crítica de Kant, la constituye la singular manera de plantear el universalismo y el consenso normativo, fundamentado en el "sensus communis". También resulta notable que en dicha obra haya caracterizado dicho "sentido", como una suerte "enjuiciamiento", que posee como instrumento normativo, lo que allí denominó, "validez ejemplar". El presente estudio sobre este peculiar modo de validez, tendrá como contrapunto una aproximación a ciertos problemas semejantes, que fueron desarrollados por la tradición retórica representada por Aristóteles. Esto permitiría ponderar ciertas relaciones, ya sea de continuidad o de discontinuidad, ya sea de semejanza o desemejanza, entre la formulación kantiana del asunto, y su tematización dentro de la retórica aristotélica. Finalmente, este esfuerzo de mediación pretende ser actualizado, gracias a la interpretación del filósofo italiano Alessandro Ferrara, quien propone la noción de "validez ejemplar" (FERRARA, 2008), como un modo de soslayar el peligroso relativismo defendido por muchas corrientes posmodernistas, apuntaladas en su particular interpretación del denominado Giro Lingüístico de la filosofía.

Para iniciar este estudio, resulta necesario presentar a grandes rasgos la propuesta interpretativa de A. Ferrara, pues en ésta el problema de la validez normativa del sentido común, se presenta en su más significativa y polémica actualidad. Su singularidad para el presente trabajo, consiste también en acentuar los elementos teórico-estructurales que se encuentran allí en juego, a la par que refiere la peculiaridad de este tipo de validez. Ambas perspectivas

\footnotetext{
${ }^{2}$ A modo de ejemplo, se pueden mencionar brevemente los múltiples estudios que en torno a la capacidad de juzgar, realizados por Hannah Arendt (2003), que siguen motivando distintas discusiones en torno a la noción de ciudadanía o de comunidad política (BEINER, 2003, 2008). De igual modo, puede mencionarse la peculiar apropiación del concepto de sentido común que viene desarrollando el sociólogo Boaventura de Souza Santos, quien en su Crítica de la razón indolente, considera que una posibilidad digna y necesaria para superar las aporías de los tiempos presentes, la constituye la posibilidad de reivindicar un "sentido común emancipador." (DE SOUZA SANTOS, 2005).
} 
justificarían ulteriores estudios, que permitiría traspasar las fronteras del formalismo subjetivo (estético), donde usualmente ha quedado marginado este tipo de validez. Y al mismo tiempo, constituyen un excepcional preámbulo, para apreciar la riqueza e intrepidez filosófica de la tercera critica de Kant.

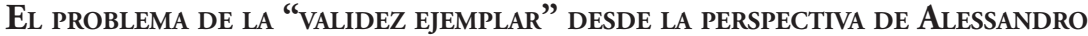 FERRARA}

La motivación principal que anima la investigación de Ferrara en torno a la noción de ejemplaridad kantiana, al igual que el de la noción de sentido común que la sustenta, tiene que ver con el peligroso relativismo defendido por ciertas corrientes del pensamiento actual, al interpretar la crítica al fundacionalismo que los filósofos del denominado Giro Lingüístico plantearon (FERRARA, 2008). Para este pensador, corrientes como los denominados Estudios Culturales, el Culturalismo Antropológico, el Postestructuralismo, etc., parecen estar condenados a "aburrirnos con su letanía de la diferencia, constantemente repetida y nunca seguida por una propuesta positiva de un nuevo modo, verdaderamente postfundacionalista, de concebir lo verdadero y lo falso, lo justo y lo injusto" (FERRARA, 2008, p. 32). Para Ferrara, si bien la crítica fundacionalista postuló la imposibilidad de un conocimiento absoluto y definitivo (supracontextual o transcontextual) que fuese más allá de cualquier espectro interpretativo, la pluralidad de éstos no puede necesariamente ser concebida desde el punto de vista del "todo vale" (FERRARA, 2008). Ya se trate de los "juegos de lenguaje" (Wittgestein), de la noción de "vocabulario" (Quine), de la idea de "tradición" (Gadamer), o de "paradigma" (Kuhn), todos ellos tienen en común el sano patrocinio de la diferencia y la pluralidad, pues no pueden reducirse a una sola unidad abarcante. No obstante, la intención última de Ferrara consiste en demostrar que es aún posible reconciliar el universalismo y el pluralismo, de tal manera que puedan plantearse legítimamente intereses comunes a la humanidad entera, al margen de los diferentes o múltiples contextos. Para ello la noción de "validez ejemplar" resulta decisiva, pues ésta no impone la cimentación de una plataforma discursiva, de carácter "privilegiado" (FERRARA, 2008).

La noción de validez ejemplar se opone positivamente a la noción de validez en términos de principios y leyes. Positivamente quiere decir, por un lado, que no se renuncia al consenso, y por otro, propone una fusión no forzada ni unilateral entre la realidad y la normatividad. Para Ferrara la fuerza 
de lo ejemplar consiste en la fuerza de lo que "es como debiera ser". En otras palabras, ella permite establecer un nexo autorreferencial entre el "mundo de lo que es" (los hechos) y el "mundo de la ideas" (las normas). Así planteada, esta propuesta revela de inmediato su origen kantiano: la capacidad del juicio reflexionante de establecer un tránsito entre lo "teórico" (el concepto de naturaleza) y lo "práctico" (el concepto de la libertad). Como se expondrá más adelante, lo ejemplar en Ferrara apunta hacia la posibilidad de concebir una "universalidad sin principios" (FERRARA, 2008), semejante a la noción kantiana de sentido común.

De manera semejante a la Crítica del juicio, Ferrara distingue entre el ejemplo como modelo (el esquematismo en Kant) y ejemplo como lo innovador (la ejemplaridad del juicio estético). Las características de este último podrían resumirse del siguiente modo: primero, la validez de éste es "autorreferencial", es decir, el principio del cual es ejemplo es formulado de manera ad hoc. Segundo, es capaz de formular nuevas perspectivas de lo que existe (lo real) o nuevas dimensiones de lo ideal (la norma). Tercero, posee tal fuerza y atracción, que más que demostrativa (lógica), puede denominársele "persuasiva" (retórica). Cuarto, ofrece la posibilidad de orientar el pensamiento, bien cuando los principios o leyes fallan en su explicación de lo real, o bien, cuando tales principios o leyes no existen (FERRARA, 2008).

Ferrara reconoce que en la modernidad, la fuerza del ejemplo o validez ejemplar fue reducida al terreno de la experiencia estética. Y mucho más aún, al fenómeno que la representa por excelencia: la belleza. Pero si se define la validez ejemplar como aquello que ejerce una "atracción irrenunciable", su ámbito de aplicación puede ampliarse a terrenos bien distintos, y en apariencia opuestos (al del puro gusto estético): ciertas experiencias morales y religiosas, el horizonte de lo político y social, la actividad económica y la práctica médica; es decir, en aquellas ocupaciones donde se presenta una "excepcional congruencia" entre el orden de su peculiar realidad, y la normatividad que le pertenece. Según Ferrara, la fuerza del ejemplo se manifiesta allí donde la conexión entre los hechos y las ideas presentan "no simplemente un entrelazamiento pasajero, ocasional e imperfecto, sino una infrecuente, duradera y casi total fusión" (FERRARA 2008, p.21). De allí que se lo pueda relacionar con cualidades de nuestra experiencia a las cuales atribuimos autenticidad, belleza, perfección, integridad, carisma, aura etc.

Basta por el momento con esta sucinta descripción, para comprender el amplio abanico de posibilidades (principalmente en el ámbito de la filosofía 
política) que ofrece esta forma de la normatividad, la singular estructura filosófico-conceptual que entrańa, y el indudable horizonte kantiano de ésta. De igual manera, salta a la vista la distancia existente entre los asuntos temáticos referidos, tanto por Kant como por Ferrara, respecto a este tipo de validez. Por un lado, la explicación de la experiencia estética en la tercera crítica, y por otro, la perspectiva política, social y cultural de su uso, en el pensador italiano. Así las cosas, surge de inmediato la siguiente cuestión: ¿resultan contrapuestos ambos horizontes del problema (el estético y el político), o es posible ajustarlos, el uno al otro, sin mayores contratiempos ni contradicciones? La aproximación que se realizará más adelante, y que posee como plataforma la retórica aristotélica (y su indudable compromiso éticopolítico), intentará responder a este interrogante.

\section{EL PROBLEMA DE LA VALIDEZ EJEMPLAR EN LA ANALítTCA DE LO BELLO}

En el cuarto momento de la analítica de lo bello, al explicar Kant la naturaleza apodíctica de la experiencia estética, señala que en ésta se presenta una suerte de "necesidad ejemplar". Al no manifestarse allí conceptos generales que avalen las pretensiones del sentimiento estético a una aprobación universal, y aunque no obstante la aspiración sea legítima y real, la Crítica del juicio, se ve obligada a utilizar dicha expresión. ${ }^{3}$ Gracias a una "necesidad" de tal índole, se postula "una necesidad de la aprobación por todos de un juicio, considerado como un ejemplo de una regla universal que no se puede dar." (CJ $\$ 18 \mathrm{~B} 62$ 63). Que esta regla no se pueda tematizar no significa su inexistencia. Por el contrario, indica la imposibilidad de especificarla conceptualmente. Así que es el mismo enjuiciamiento concreto, vale decir, la experiencia estética directa, la que se eleva como principio de determinación. Para ratificarlo, presenta Kant en el $\$ 22$ su "propio y particular" juicio de gusto como "ejemplo" de una suerte de sentido común que debe asegurar el carácter apodíctico de los juicios de gusto. En conclusión, pareciera que es el mismo enjuiciamiento estético el que se alza como la expresión más acabada de tal sentido comunitario. Y esto quiere decir que éste representa por sí y desde sí mismo, una generalidad que no puede distinguirse de su aplicación concreta.

\footnotetext{
${ }^{3}$ En adelante se citara la Crítica del juicio, utilizando sus iniciales $(C J)$, luego se escribirá el parágrafo en cuestión (\$), y a continuación la paginación de la Akademie-Ausgabe (B\#). El texto citado, parafraseado o comentado proviene de la traducción de M. García Morente. KANT, E. Crítica del juicio. México: Porrúa, 1991.
} 
Este recurso de la ejemplaridad representa únicamente un caso de las enormes dificultades con las que tropieza el lenguaje crítico-trascendental al intentar definir las extrańas características del juicio de gusto. Para ello Kant se ve obligado a hablar de una suerte de "voz" o "voto" general, o lo que es lo mismo, de una especie de "validez común" que, como contrapartida a idénticas aspiraciones lógicas de los demás juicios (el moral y el cognoscitivo), harían comprensible pretensiones similares en el horizonte de lo estético. Todas estas expresiones tienen por objeto seńalar que, cuando se posee un auténtico sentimiento estético, su aprobación por todo otro sujeto se experimenta con el mayor convencimiento. El enjuiciamiento estético no espera su confirmación gracias a unos conceptos o imperativos que así lo obliguen, sino más bien, como lo refiere en el $\$ 8$, por la "adhesión" de todo otro individuo. Y aunque ningún canon del gusto pueda ser reconocido como determinante dentro de dicha experiencia, la certidumbre que allí embarga al sujeto se funda en lo que Kant denomina "regla de aplauso". Finalmente, y cuando rodeos como las anteriores resultan insuficientes, la utilización del recurso analógico del "como si”“, constituye otra estrategia para obtener resultados semejantes: así, del mismo modo que la determinación lógica de los enunciados teórico-prácticos pretende explicar su legítima aspiración a una generalidad y apodicticidad, otro tanto se esperaría de los enunciados estéticos, aunque manteniendo la atención sobre sus profundas diferencias. En definitiva, pareciera que es la ausencia de una terminología propia para este tipo de problemas, lo que hace tan arduo la asimilación de las soluciones kantianas.

Desde el horizonte de la lógica-trascendental kantiana, la validez de la experiencia estética así concebida, vale decir, como "ejemplar", constituye un asunto de compleja asimilación. Y lo mismo podría afirmarse de toda aquella serie de expresiones gracias a las cuales la Crítica del juicio intenta describirla: "validez común", "voto general”, "regla de aplauso", o incluso, la noción misma de "sentido común”. Ahora bien, ¿qué otras perspectivas se pueden explorar para que expresiones tan problemáticas como éstas, puedan ser explicitadas de manera más amplia? Más arriba se ha sugerido que el recurso a la tradición

\footnotetext{
${ }^{4}$ Herman Parret asegura que el recurso al como si, inaugura la perspectiva de un pensamiento analógico en Kant. Además, puntualiza que este horizonte del como si tiene como consecuencia "una cierta retorización de la argumentación" (PARRET, 1991, p. 94). Por otra parte, Parret refiere allí una reflexión sobre Kant, tomada del texto de Alexander Kojéve, bien elocuente al respecto: "La introducción en la filosofía de la noción del como sí es sin duda alguna una astucia notable, digna del astuto anciano que fue Kant al decir de algunos [...]. Astucia o hipocresía, lo cierto es que Kant fue el primero en introducir en la filosofía esta noción y el desarrollo bajo el modo del como sí." (PARRET, 1991, p. 95-96).
} 
aristotélica de la retórica, permitiría encontrar congruencias temáticas y estructurales entre la fundamentación kantiana de la normatividad estética, y al igual que con la noción de ejemplaridad ofrecida por Ferrara. Aquí se podría adelantar de momento, que esta misma tradición puede contribuir al esclarecimiento de esta extrańa terminología. Por lo pronto conviene continuar la exploración sobre este tipo de validez normativa, siguiendo la estructura misma de la exposición crítico-trascendental ofrecida por Kant. A continuación, y a partir del estudio de la denominada deducción de los juicios estéticos, se seguirán acumulando elementos de análisis que justifiquen un rodeo por dicha tradición.

\section{DEDUCCIÓN DE LOS JUICIOS ESTÉTICOS: SENTIDO COMÚN Y VALIDEZ EJEMPLAR}

Según la filosofía crítico-trascendental, cualquier pretensión a una validez necesaria y universal de cualquier enjuciamiento, requiere de una legitimación que los justifique, vale decir, de una "deducción" de sus aspiraciones. Como en la experiencia estética no se trata de justificar la realidad objetiva de concepto alguno, y por el contrario, se trata de "una satisfacción que debe ser declarada regla para cada uno" ( $C J \$ 31$ B134), para Kant la deducción constituye un problema bastante "fácil" de desarrollar (CJ \$38 B152-153). Bastaría simplemente exponer la relación subjetiva entre las facultades (imaginación y entendimiento), que generan el sentimiento de gusto. Precisamente porque los juicios de gusto pasan "por encima del concepto y hasta de la intuición del objeto” ( $C J \$ 36$ B148-149), y añaden a éste una satisfacción que es exigible $a$ priori, se trata de encuadrar el problema dentro del asunto más general de la filosofía trascendental: ¿cómo son posibles los juicios sintéticos a priori? ( $C J$ $\$ 36$ B147-148).

Como en este tipo de enjuiciamientos se manifiesta la condición más general de todo enjuiciamiento de objetos (la coincidencia no intencionada entre entendimiento e imaginación), y ésta, a su vez, puede ser admitida a priori como valedera para cada cual (vale decir, "común” a todos) (CJ $\$ 38$ B151), para Kant la legitimidad de la pretensión de aquellos quedaría demostrada. Y como la expresión de esta condición no puede manifestarse más que a través de un "sentimiento", el camino hacía un sentido común queda suficientemente despejado. Por tal razón, la capacidad de juzgar en cuanto tal constituye el principio subjetivo de los juicios de gusto. O en términos de la 
representación misma, dicho principio refiere la subjetiva finalidad de la forma del objeto para la facultad de juzgar (CJ. \$38 B151-152).

La "facilidad" que Kant le atribuye a esta deducción, consiste pues en derivar la posibilidad de los juicios de gusto, "de la naturaleza de esa facultad como facultad de conocimiento." ( $C J \$ 34 \mathrm{~B} 142)$. O lo que es lo mismo, la capacidad de juzgar en cuanto tal constituye el principio subjetivo de los juicios estéticos. Aún más, según el $\$ 34$ de esta misma deducción, el juicio estético es "objeto al par que ley" (CJ\$36 B148-49). Esta afirmación ratificaría, como ya se ha sugerido, que la experiencia concreta de la belleza (llámese un caso, un hecho, o un ejemplo), representaría por sí misma la generalidad de ese sentido común. ${ }^{5}$ En palabras de Kant, la tarea de esta deducción, al poner al descubierto la naturaleza y el papel de la facultad de conocer en los juicios de gusto, permitiría extraer "la idea de un sentido que es común a todos." (CJ $\$ 40$ B157-158). La experiencia misma de la belleza o el juicio estético encarnarían así, en su carácter concreto y particular, la norma misma ("objeto al par que ley") de su determinación. O en otros términos, la experiencia misma de la belleza se alzaría como "norma ejemplar".

Para efectos del desarrollo posterior, resulta valioso destacar aquí otras consideraciones kantianas, que amplían las peculiaridades de este tipo de enjuiciamiento. Para Kant, si bien esa relación de las capacidades de conocimiento se deja legitimar de manera tan simple, en un juicio estético concreto "la subsunción puede fácilmente errar." (CJ\$38 B152-153). Empero, resulta notable que a renglón seguido puntualice que, a pesar de ello, "[...] no por eso se le quita algo a la legitimidad de la pretensión del Juicio de contar con una aprobación universal” ( $C J \$ 38$ B152-153). Resulta llamativo que en esta deducción, y a diferencia de las deducciones de los trabajos críticos anteriores, la quid facti (el juicio de gusto concreto), resulta más ardua que la quid juris. Precisamente porque en la experiencia de la belleza no existe principio objetivo alguno (llámese canon, modelo o ideal), que pueda determinar dicha experiencia, y por el contrario, se manifieste allí una pura relación subjetiva entre las facultades, la subsunción o determinación correcta "tiene dificultades inevitables" ( $C J \$ 38$ B152-153). Resulta evidente que la ausencia de un principio objetivo hace que la determinación de esa relación de las facultades sea ardua, y hasta compleja. Y sin embargo, aquellas "dificultades" no parecen una deficiencia de la experiencia estética. Al contrario, podrían considerárselas

${ }_{5}^{5}$ Ferrara coincide con esta apreciación del fenómeno, cuando habla de la "suprema atracción" que ejerce la belleza, cuya experiencia puede elevarse a la categoría de lo "ejemplar" (FERRARA, 2008). 
una virtud de ésta, en tanto que, a pesar de todo, representa o ejemplariza la generalidad del sentido común

En este momento de la argumentación resulta inevitable indagar por el valor que la deducción le asigna a la ejemplaridad, extricto sensu. Si se atiende al $\$ 34$ donde Kant ratifica que ante la imposibilidad de modelos o principios generales para el gusto, no queda para éste más que la posibilidad de la crítica $(C J \$ 34$ B144), declara a renglón seguido que esta situación no disculpa la necesidad de una "rectificación y extensión" para tales juicios. Si se pretende indagar por la peculiar estructura y funcionamiento que siguen las facultades (imaginación y entendimiento) dentro de esta experiencia, Kant indica que es necesario "analizar con ejemplos [esa] finalidad subjetiva recíproca” (CJ \$34 B141-142). Es por esto que allí mismo define a este tipo de "crítica", como "el arte o ciencia de traer a reglas" esta mutua relación ( $C J \$ 34$ B142-143). A renglón seguido, Kant distingue dos modalidades desde las cuales puede asumirse una crítica del gusto: como "ciencia", "cuando la posibilidad de semejante juicio la deduce de la naturaleza de esa facultad [el juicio]", o como "arte", "cuando muestra eso por medio de ejemplos" (CJ\$34 B142-143). ${ }^{6}$

Podría considerarse entonces, que la primera (como crítica “trascendental”), sería allí la vía adecuada para la deducción. Y sin embargo, como se ha señalado más arriba, esta perspectiva promovería una concepción del sentido común de tipo privativo: por muchas "dificultades inevitables" que se presenten, habría que abstraer las condiciones privadas de acceso a la experiencia estética. En cambio en la "crítica como arte", que "trata solamente de aplicar al juicio las reglas fisiológicas [...] y, por tanto, empíricas, según las cuales el gusto, 'en realidad', procede” (CJ \$34 B142-143), tendría la ventaja de ofrecer unos casos o juicios estéticos particulares, cuya peculiaridad haría posible una comprensión concreta de la generalidad del sentido común. Sin embargo, aunque el ejemplo o juicio ejemplar, dada su naturaleza empírica, privada y particular, pueda errar, fallar o equivocarse, "no por eso se le quita algo a la legitimidad del juicio" ( $C J \$ 34$ B142-143).

Queda así aclarado que, más que uno entre distintos casos de subsunción judicativa, los ejemplos representarían un procedimiento "no tematizable” de determinación estética. La tarea crítica de traer a reglas esa

\footnotetext{
${ }^{6}$ Laura Quintana plantea el problema en términos de una doble legitimación que se presenta en la Crítica del juicio: una débil y una fuerte. Veremos más adelante como aquella considerada débil nos permitirá una desplazamiento hacía la retórica; mientras la fuerte sigue los lineamientos más generales de la filosofía crítico-trascendental (QUINTANA, 2008, p. 249).
} 
relación recíproca entre las facultades, denominada sentido común, resulta pues inseparable de su determinación. Es por esto por lo Kant insiste en que, en la crítica como ciencia, el juicio de gusto es 'objeto al par que ley' ( $C J \$ 36$ B148-49). En cambio, desde de la crítica como arte, no se podrían dar pruebas de dicho sentido más que mediante su propio juicio de gusto. Para efectos del presente trabajo, la ventaja de la crítica como arte radicaría en que se soslayaría una concepción del sentido común, concebida únicamente en términos de la correlación y disposición formal entre imaginación y entendimiento. Y así, según la argumentación hasta aquí desarrollada, el sentido común despunta como una plataforma judicativa cuya generalidad supera cualquier abstracción, y que únicamente en su concreción empírica puede manifestarse plenamente. ${ }^{7}$

El resultado hasta aquí alcanzado, gracias a este rodeo en torno al carácter ejemplar de los juicios de gusto, no se agota en destacar esta peculiar manera de la normatividad. Aquí se pretende mostrar también, cómo gracias a ese mismo recurso, se genera el convencimiento que subyace a las pretensiones de tal enjuiciamiento. En otras palabras, se espera hacer comprensible esa suerte de certeza que embarga al sujeto, y que, sin principios generales y con apenas un juicio empírico-singular, le permite la seguridad del asentimiento permanente de los demás sujetos. Para ello será de suma importancia continuar con otra de las exigencias de la filosofía crítico-trascendental kantiana, vale decir, la dialéctica. Pues es en la dialéctica de los juicios de gusto, dada la cercanía de esta "lógica de la apariencia" con los fundamentos de la retórica de cuño aristotélico, donde podrán ampliarse tres de los asuntos propuestos en el presente trabajo. Primero, esclarecer el significado y alcance de esa extraña terminología, señalada ya en la analítica. Segundo, ajustar el planteamiento de la estética kantiana, con las reflexiones de Ferrara en torno a la validez normativa atribuida a la ejemplaridad. Y tercero, hacer comprensible la capacidad que esta forma de la validez posee, como para inducir o promover a través del sentimiento de los demás, cierto consenso. ${ }^{8}$

\footnotetext{
${ }^{7}$ Kant, a propósito de la universalidad de los juicios de gusto, señala que se trata de encontrar en "una única tulipa bella”, una satisfacción con la pretensión a universal validez (CJ\$33 B141-142).

${ }^{8}$ Debe señalarse aquí que la siguiente confrontación con la retórica aristotélica, puede justificarse también gracias al estudio que Gadamer ha realizado en Verdad y método I. Allí Gadamer investiga los orígenes humanísticos de los conceptos kantianos de sentido común y juicio reflexionante, entre otros; y señala igualmente que esta tradición humanista (siglos XV a XVII), posee una deuda incuestionable con la retórica antigua, en especial con Aristóteles (GADAMER, 1990, p. 38-74).
} 


\section{DiALÉCTICA Y RETÓRICA: VALIDEZ COMÚN Y ENTINEMA (c่v $\theta \dot{v} \mu \eta \mu \alpha)$ RETÓRICO}

Antes de abordar las antinomias del juicio de gusto, que constituyen el núcleo de esta dialéctica de los juicios de gusto, conviene referir algunas características que en Aristóteles posee el "arte retórico", que permitirán ponderar la viabilidad de dicho desplazamiento. Hablando de la especificidad del arte retórico, el libro I de la Retórica afirma que "la tarea de esta última versa, por lo tanto, sobre aquellas materias sobre las que deliberamos y para las que no poseemos artes específicas" (Rhet. 1357a) ${ }^{9}$. Deliberar significa aquí, como se añade a renglón seguido, discutir sobre "lo que parece que puede resolverse de dos modos." (Rhet. 1357a 5). Para Aristóteles, sólo "aquellas cosas que a menudo pueden ser de otra manera" (Rhet. 1357a 15), constituyen los asuntos propios de esta disciplina. En cambio sobre aquellos asuntos que poseen un carácter apodíctico, resultaría absurda cualquier forma de discusión.

Resulta aquí significativo constatar cómo los problemas que genera la experiencia de la belleza, parecen adaptarse bastante bien a dichas condiciones. Si de la belleza, según Kant, no puede existir ni canon ni ciencia, o parafraseando a Aristóteles, "no poseemos artes específicas", ¿no significa que el gusto estético constituye un ámbito de discusión y de deliberación permanente? Por otra parte, ¿̇no refiere el $\$ 16$, que la experiencia estética puede, según la definición aristotélica, "resolverse de dos modos"? O en palabras de Kant, el enjuiciamiento puede ser correcto "según lo que se tiene ante los sentidos... [o]... según lo que se tiene en el pensamiento" (CJ\$16 B52-53). ${ }^{10}$

Según estos paralelismos, pareciera legítimo seguir avanzando en la dirección indicada. A pesar de ello, resulta conveniente escuchar al propio Kant, y su ponderación del arte retórico. Según el $\$ 53$, la retórica:

en la medida en que por tal se entiende el arte de persuadir, esto es, de engañar a través de la bella apariencia (como ars oratoria); [constituye] una dialéctica que sólo toma a préstamo del arte poético cuanto le es necesario a objeto de ganarse, en provecho del orador, los ánimos [de los oyentes] antes del enjuiciamiento y hurtarles a éstos la libertad. (CJ\$53 B216-217).

\footnotetext{
${ }^{9}$ En adelante utilizará la metodología de Bekker, para citar las obras de Aristóteles referenciadas en este trabajo.

${ }^{10}$ Kant añade que, mediante esta distinción, "se podrían arreglar algunos disentimientos entre los jueces del gusto" ( $C J \$ 16 \mathrm{~B} 52-53)$. Esto no quiere decir que se puedan establecer reglas generales, pues, como comenta Kant a propósito de ciertas consideraciones estéticas de Hume, "a pesar de que los críticos [...] puedan disputar más espaciosamente que los cocineros, tienen, sin embargo, la misma suerte de éstos" (CJ\$34 B143).
} 
La perspectiva de un análisis comparado parecería así más bien un desacierto, teniendo en cuenta una calificación tan peyorativa. A pesar de esto, habría que puntualizar que estos reparos kantianos se encuentran al margen del presente trabajo, pues aquí no se pretende ponderación moral alguna sobre los efectos de la persuasión retórica (pérdida de 'libertad'), ni mucho menos, se persigue una evaluación estética de su configuración discursiva (ars oratoria). Como lo ratifica el título del parágrafo, comparación del valor estético de las bellas artes entre sí, su intención es la confrontación y subsiguiente jerarquización entre las artes bellas, y no las "aporías" dialécticas que bien pudiese suscitar la experiencia o disfrute de cada una de éstas.

En concordancia pues con su definición crítico-trascendental de la dialéctica, descubre Kant que también en los juicios de gusto se manifiestan ilusiones o apariencias lógicas que resulta imperativo despejar $(C J \$ 55 \mathrm{~B} 232)$. Estas contradicciones no le incumben tanto al juicio concreto, sino a los principios de la facultad misma, que bien podrían generar "una antinomia que haga dudosa su conformidad a ley, y, por tanto, también su interior posibilidad" ( $C J \$ 55$ B232-233). Así, el que “cada uno tenga su propio gusto.” (CJ \$55 B232-233), y por tanto, a falta de conceptos, no se pueda "disputar"; tiene como contrapartida dialéctica, una proposición igual de incuestionable: como sobre el gusto sí se puede "discutir", entonces dicho enjuiciamiento debe fundarse en conceptos ( $C J \$ 56$ B234-235). Para Kant el camino para la solución de esta antinomia posee así un doble aspecto: uno "crítico-trascendental", y otro, que podría designarse, "vulgar" o mundano.

Según este última perspectiva (la vulgar o común), habría que distinguir entre el disputar y el discutir, pues teniendo ambas nociones como objetivo, "el producir unanimidad mediante la oposición reciproca de juicios" (CJ\$56 B233-234), el disputar exige de conceptos objetivos, mientras en el discutir, éstos no son necesarios. Bastaría entonces, según Kant, tomar una fórmula que, "si bien no está proverbialmente en circulación, está, sin embargo, en el sentido de todos, a saber: sobre el gusto se puede discutir (aunque no disputar)" (CJ \$56 B233-234) ${ }^{11}$, para salvar dicha ilusión dialéctica. Por otro

\footnotetext{
${ }^{11}$ A propósito de esta fórmula que, "si bien no está proverbialmente en circulación, está, sin embargo, en el sentido de todos, a saber: sobre el gusto se puede discutir (aunque no disputar)", la retórica antigua tenía como instrumento para la elaboración de la persuasión, la denominada tópica. Ésta propone en unos horizontes generales de indagación, comunes a todos los individuos. La retórica latina la tradujo como los loci, o "lugares comunes", que consistían más o menos en un conjunto de creencias compartido por una comunidad. Tal vez a tal sistema se refiera Kant, al indicar que tales "fórmulas se encuentran proverbialmente en el sentido de todos" (CJ \$56 B233-234).
} 
lado, según la vía crítico-trascendental, no resulta allí necesario aclarar el contenido semántico entre el discutir y el disputar, ya que según Kant, éste contenido se encontraría en el "sentido de todos". Más bien sería suficiente para el filósofo trascendental, poner de manifiesto los dos significados que puede poseer el valor del concepto. Como el juicio de gusto no posee conceptos "determinados" en su fundamento, no resulta necesario disputar; pero si es posible discutir, ya que Kant encuentra motivos para sospechar que detrás del juicio de gusto se hallan involucrados conceptos "indeterminados" de la razón. Y a semejanza de lo que sucede en las correspondientes dialécticas de las otras dos obras críticas anteriores, resulta necesario "mirar por encima de lo sensible y buscar en lo suprasensible” (CJ\$57 B236-237), para deliberar en cuestiones como éstas, vale decir, en asuntos "que pueden resolverse de dos modos distintos".

Planteada así la antinomia de los juicios de gusto, resulta valioso seguir indagando sobre la conveniencia que poseería el establecer un enfoque retórico alrededor este tipo de ilusiones. Aquí de nuevo se debe recurrir a las palabras de Aristóteles. Según éste:

La retórica es antíestrofa (correlativa) a la dialéctica, ya que ambas tratan de aquellas cuestiones que permiten tener conocimientos en cierto modo comunes a todos y que no pertenecen a ninguna ciencia determinada. Por ello, todos participan de alguna forma de ambas, puesto que, hasta un cierto límite, todos se esfuerzan en descubrir y sostener un argumento e, igualmente, en defenderse y acusar. (Rhet. 1354a). ${ }^{12}$

Que la retórica sea correlativa a la dialéctica, no implica posea una reciprocidad semejante con la dialéctica kantiana. No obstante, cuando en los Tópicos afirma que son también problemas de la dialéctica, "aquellas cuestiones de las que hay argumentaciones contrarias (pues hay dificultad en saber si es así o no es así, al haber argumentos convincentes acerca de lo uno y de lo otro)" (Tóp., I, 2, 101a 35-36), coinciden Kant y Aristóteles en la competencia de esta disciplina para despejar contradicciones (antinomias), que ciertas proposiciones o situaciones fomentan. Semejante concurrencia justificaría la mediación entre la retórica y la estética kantiana que se vienen proponiendo. Y aunque ambas disciplinas (retórica y dialéctica) se encaminen

\footnotetext{
${ }^{12}$ Quintín Racionero, traductor y comentarista de la Retórica aristotélica, asegura que el término griego antistrofa, remite a una relación de oposición-complementación, y por tanto, apunta a un contenido que es mucho más amplio. Según esto, antistrofa indica que entre la retórica y la dialéctica se presenta una relación simultánea de identidad y de oposición (RACIONERO, 1990, p. 161).
} 
hacia aquello que es materia de permanente deliberación, continua Aristóteles, se diferencian en que la dialéctica procedería mediante el silogismo, y la retórica

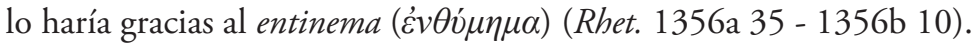

Antes de precisar lo que ha de entenderse por entinema, se podría anticipar que en la dialéctica de los juicios de gusto, la vía seguida por el filósofo trascendental parecería estar mucho más cercana al denominado silogismo. Y es precisamente porque las antinomias del gusto arriba mencionadas constituyen cuestiones "de las que hay argumentaciones contrarias (pues hay dificultad en saber si es así o no es así, al haber argumentos convincentes acerca de lo uno y de lo otro)" (Tóp., I, 8, 104b 10-15), por lo que requieren de un método de naturaleza dialéctica, al decir de Aristóteles. Por lo demás, tal método precisaría de las cualidades inherentes al "sabio" o al lógico ("el filósofo trascendental").

En cambio aquella vía que se ha denominado "vulgar", estaría más cercana al denominado entinema, como se examinará más adelante. Y es que, mientras el primero recurría al "fundamento común" que se encuentra detrás, tanto de los conceptos determinados como indeterminados de la razón, vale decir, lo "suprasensible", el segundo procedimiento apelaba más bien a una noción comúnmente aceptada por el "sentido de todos". ${ }^{13}$

Así que sería esta manera de referirse al sentido de todos, a propósito de esos conocimientos comunes, lo que justificaría esta mediación retórica, para esclarecer ese convencimiento que embarga al sujeto, cuando a partir de un juicio estético particular y concreto, se sabe vinculado a la totalidad de los demás sujetos. ${ }^{14} \mathrm{Y}$ es que, hablando de la utilidad de la retórica, Aristóteles menciona que, cuando se trata de algunas gentes, "ni aún si dispusiéramos de la ciencia más exacta, resultaría fácil, argumentando sólo con ella, lograr persuadirlos, pues el discurso científico es propio de la docencia [...] y más bien se necesita que las pruebas por persuasión y los razonamientos se compongan por medio de nociones comunes" (Rhet. 1355a 25-30). Por último, y aunque los mecanismos lógico-argumentativos estén encaminados hacía una "demostración" que despeje cualquier malentendido o contradicción, la

\footnotetext{
${ }^{13}$ Es decir, a aquella fórmula que, si bien no es para Kant ni una máxima ni un proverbio popular, constituye parte de un patrimonio común. Pero como tampoco puede determinarse conceptualmente, no puede ser justificada más que al modo de un sentido. Vale decir, "sobre el gusto se puede discutir, aunque no disputar." (CJ\$56 B233-234).

${ }^{14}$ Para los profesores Germán Vargas y Luz Gloria Cárdenas, "la retórica es una teoría de la comunicación persuasiva, es el intento de hacer que los intereses y las acciones motivadas por ellos sean encaminados a una sociabilidad común" (VARGAS; CÁRDENAS 2005, p. 75).
} 
retórica no resulta menos valiosa, pues al decir de Aristóteles, "la persuasión es una especie de demostración" (Rhet. 1355a 5-10). ${ }^{15}$

Ahora bien, Aristóteles entiende el entinema como un silogismo abreviado, o a lo sumo, como silogismo incompleto. Esta incompletitud no obedece a razones de descuido por parte del orador; más bien ésta tiene que ver con ciertos objetivos retóricos, vale decir, para agilizar los procedimientos oratorios encaminados hacia la persuasión. Esto no significa que al oyente se le niegue o sustraiga cierto tipo de información fundamental para dentro del proceso de recepción. El orador más bien se abstiene, pues dicha información puede suponerse común o conocida de alguna manera por el auditorio. O lo que sería lo mismo, estaría en el sentido de todos. ${ }^{16}$ De allí el que el entinema corresponda más bien a la vía que hemos llamada vulgar, pues como lo señala allí Kant, dicha fórmula "si bien no está proverbialmente en circulación, está, sin embargo, en el sentido de todos” (CJ \$56 B233-234). En cambio el silogismo propiamente dicho, correspondería más bien a la vía del filósofo trascendental o la del sabio, según se deduce en Kant y Aristóteles.

En este momento resulta necesario indagar si los asuntos vinculados al placer estético, pueden incluirse dentro de la órbita de los problemas propios de la Retórica. Aristóteles señala que la meta principal de ésta, consiste en ahorrarle perjuicios a la polis (Rhet. 1355b 5), y por tanto, estaría vinculada con "aquel saber práctico sobre los caracteres al que es justo denominar política" (Rhet. 1355a 25 - 1356a 30). Sin embargo, como su tarea es "reconocer lo convincente de lo que parece ser convincente", añade que en sentido estricto, "la retórica no pertenece a ningún género definido." (Rhet. 1355b 5-15). Si la Retórica pues, no pertenece a género definido alguno, la experiencia de la belleza, y todo lo que en esta experiencia pueda ser objeto de deliberación y confusión, podrían estar igualmente dentro de su ámbito.

\footnotetext{
${ }^{15}$ A propósito de esta característica de la retórica, vale la pena señalar una importante consideración realizada por Perelman y Olbrechs-Tyteca: "Todo discurso que no pretenda a una validez impersonal tiene que ver con la retórica. Desde que una comunicación tiende a influir sobre una o varias personas, a orientar su pensamiento, a excitar o calmar emociones, a dirigir una acción, ella es dominio de la retórica." (PERELMAN; OLBRECHS-TYTECA, 1989, p. 211).

${ }^{16}$ Aristóteles puntualiza que: "Es necesario que el entinema y el ejemplo versen sobre aquellas cosas que a menudo pueden ser de otra manera y que [...] el ejemplo sea una inducción y el entinema un silogismo, y <todo ello > a partir de pocas premisas, incluso menos de las que consta el silogismo de la primera figura. Porque si alguna de estas premisas es bien conocida, no hace falta enunciarla; el propio oyente la suple." (Rhet. 1357a 15-19).
} 
Pero por otra parte, se podría también reprobar que la experiencia estética tiene un espacio de análisis más adecuado en el tratado sobre la Poética, que en el tratado de la Retórica. No obstante, retomando el problema más general hasta aquí planteado, resulta que no es un asunto temático lo que se encuentra en cuestión (la experiencia estética), sino más bien una "inquietud" lógico-dialéctica dentro de las pretensiones de tal sentimiento (la validez ejemplar de un juicio particular que puede generar puntos de vista contrapuestos). Esta afirmación puede ratificarse cuando Aristóteles puntualiza que, en esta disciplina se trata de "establecer teóricamente lo que es convincente en cualquier caso que se proponga, razón por la cual afirmamos que en lo que ella concierne como arte no se aplica sobre ningún género específico." (Rhet. 1356b 5-15).

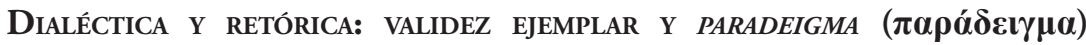 RETÓRICO}

Retomando la indagación sobre el problema de la ejemplaridad, y luego de explorar su posible mediación a través de la retórica, el tratado aristotélico señala que, además del entinema como instrumento persuasivo, existe también otro un mecanismo de alcance similar, denominado por Aristóteles, parádeigma. Según el Diccionario de la Real Académica Española de la Lengua, la versión más común de este término (parádeigma), sería la de ejemplo o ejemplar. En concordancia con la dialéctica, señala Aristóteles que "llamo, pues, entinema al silogismo (syllogismós) retórico y ejemplo (parádeigma) a la inducción (epagogé) retórica” (Rhet. 1356a 35 - 1356b 10). Y aunque el entinema sea para Aristóteles, "la más firme de las pruebas por persuasión", los discursos basados en ejemplos no dejan de ser, "menos convincentes" (Rhet. 1355a 5-10). De otra parte, ambos participan de la estructura lógicoargumentativa de la retórica, así que dependen de la configuración misma del discurso, y no de las características psicológicas del orador o de su auditorio (Rhet. 1355a 5-10). Pero si alguna diferencia entre ambas puede plantearse en términos persuasivos, ésta radica en que "logran mayor aplauso los [discursos] que se basan en entinemas" (Rhet. 1356b 20-25).

Pues bien, una explicitación mucho más amplia sobre la estructura y dinámica del parádeigma o ejemplo, podría hacer más concluyente su paralelismo con la ejemplaridad kantiana. Lamentablemente la explicación aristotélica en la Retórica no nos ofrece una tematización más clara y precisa. 
El tratado simplemente afirma que, constituyendo el ejemplo una inducción (epagogé) retórica, "no hay aquí una relación de la parte con el todo, ni del todo con la parte, ni del todo con el todo, sino de la parte con la parte y de lo semejante con lo semejante, [...] donde una es más conocida que las otras" (Rhet. 1357b 25-30). Sin embargo, la nota aclaratoria del traductor y comentarista del tratado, Quintín Racionero, lanza cierta luz al respecto. Tomando como referencia los Analíticos primeros, precisa que, "mientras en la inducción propiamente dicha se demuestra partir de todos los casos individuales [...], el ejemplo no utiliza todos los casos individuales para su demostración" (Rhet. 1998, 174). Esto no significa, continúa, que tal inducción sea incompleta; por lo que Racionero prefiere más bien denominarla "implícita" (al igual que el entinema). En otros términos, presupone el saber o conocimiento de algo, que en la enunciación del ejemplo se supone como ya sabido (Rhet. 1998, 174). ${ }^{17}$

Pero quizás sean los ejemplos de carácter histórico que Aristóteles ofrece respecto a esta ejemplaridad (parádeigma), los que, llamativamente ofrecen una mejor comprensión de su estructura, tanto formal como persuasiva. Parafraseando a Aristóteles: si se afirma o se sospecha que Dionisio pretende a la tiranía, ya que ha pedido una guardia personal, la fuerza persuasiva de este enunciado se obtiene porque, tanto Pisístrato como Teágenes, constituyen "ejemplos" históricos de gobernantes que así lo hicieron (Rhet. 1357b 30-35). Por tal razón, "todos estos casos quedan bajo la misma proposición universal de que quién pretende la tiranía, pide una guardia” (Rhet. 1357b 25-30). Aquí puede repararse que no se presenta una universalidad proveniente de inducción completa. Más bien dicha universalidad es algo a lo que el ejemplo apunta, y que depende de ese pasado comúnmente conocido por el auditorio (implícito), representado por las historias de Pisístrato y Teágnes. Es por esto que el mismo Aristóteles afirma que los razonamientos persuasivos, "se compongan de nociones comunes" (Rhet. 1357b 30-35). ${ }^{18}$

\footnotetext{
${ }^{17}$ Los profesores Germán Vargas y Luz Gloria Cárdenas apuntan: "En cierto modo la diferencia estriba en que el ejemplo se soporta en el como si... que regula tanto al símil, como a la analogía y la metáfora [...] la inducción se reduce al si [...], esto es, aísla el cómo; en ella, pues, hay condicionalidad; en el ejemplo se simula la condición." (VARGAS; CÁRDENAS 2005, p. 112).

${ }^{18}$ Este poder persuasivo de los ejemplos tiene un gran significado en el todo de la reflexión que Vico realiza sobre la cultura, la historia y la filosofía, particularmente en su teoría de los "universales fantásticos", que el humanista italiano presenta como elementos de "ejemplaridad retórica" con carácter vinculante (VICO, 2002, 2004). Podría señalarse entonces, que Vico representa el último coletazo de la retórica antigua, al interior mismo de la consolidación del racionalismo moderno. Por tanto, siguiendo la argumentación de Gadamer, dicha terminología retórica debía estar aún presente
} 
En este estado del asunto parece que ya están todas condiciones para evaluar el paralelismo entre la ejemplaridad retórica y la ejemplaridad estética. Según el párrafo anterior, en el parádeigma se presentaría lo universal, pero en un modo de presencia que no puede separarse del aspecto concreto de lo enunciado en él. Al fin y al cabo tiene su origen en una semejanza, y no obstante para Aristóteles, constituye una forma de convencimiento ("persuasión") para nada desdeńable. De igual modo, Kant no sólo utiliza este recurso sino que también lo autoriza cuando indica que para una crítica del gusto, resulta igualmente válido seguir la vía de una indagación crítica, entendida ésta como arte. ${ }^{19}$ Así, el uso de ejemplos, a la par que explicaría la especificidad del gusto estético, permitiría igualmente dar testimonio de una forma de validez normativa que involucra a un "todo" (sentido común), y por tanto, proyecta la certidumbre de su corrección. No debe olvidarse tampoco el ya mencionado $\$ 22$ donde, al indicar ese "deber" condicionado que postulan los enjuiciamientos fundados en el sentido común, sanciona que ante semejantes pretensiones, "doy yo aquí mi juicio de gusto como ejemplo, y por lo cual le concedo validez ejemplar” ( $C J \$ 22$ B67-68). Añadiendo a continuación que dicho ejemplo, "es por tanto, una mera norma ideal, bajo cuya suposición podríase con derecho convertir en regla para todos un juicio que concordara con ella” (CJ\$22 B67-68).

Ejemplar no puede significar aquí el que la íntima certeza que procura, obligue a priori a todo otro sujeto. Por el contrario, la fórmula promueve una invitación a realizar cada uno la experiencia de lo bello, para así descubrir en la experiencia misma una suerte de convencimiento, que se impondría como si de una regla se tratara. ¿No puede reconocerse aquí una suerte de persuasión tal cual lo legitima la retórica aristotélica respecto a los ejemplos, pero bajo la perspectiva del gusto? Debe precisarse, no obstante, que todo proceder retórico, llámese entinema o paradeigma, posee una naturaleza discursiva (Rhet. 1355b 35). ${ }^{20}$ Pero si se advierte que en el comportamiento estético se manifiesta un libre e indeterminado juego entre las facultades superiores del ánimo (entendimiento, imaginación, e incluso la razón), entonces el juicio gusto particular que lo representa al modo de una regla ejemplar, no se encontraría

en el ambiente intelectual de la época, del cual Kant fue un gran observador (GADAMER, 1985). En esta misma perspectiva, pueden consultarse los trabajos de Ernesto Grassi (GRASSI, 1982; 2003).

${ }^{19}$ Debe recordarse aquí como en el $\$ 34$, Kant considera que la crítica puede llamarse arte, cuando permite explicar la relación de las facultades en el juicio estético mediante ejemplos.

${ }^{20}$ Allí dice Aristóteles que entre las pruebas por persuasión retórica, existen aquellas que pueden obtenerse "por el discurso mismo" (Rhet. 1355b 35). 
demasiado lejos de dicha exigencia discursiva. Y aún más, aunque Kant encuentre que encanto y emoción ( $C J \$ 14$ B 43-44) (inclinaciones privadas), constituyen limitantes cuyos problemas de abstracción generan dificultades inevitables para el análisis del sentimiento estético, reconoce también que no hacen ilegitimo la postulación de un sentido común, universal y necesario. En definitiva, la presencia en el juicio estético de emociones, que a primera vista lo distanciaría de aquella condición discursiva de la retórica, lo vincularían más aún a ésta. Y es que para Aristóteles, otra función de la retórica la constituye el persuadir a través del pathos. ${ }^{21}$

Dejando al margen el que tanto los paredeigmas como los entinemas persigan en Aristóteles un objetivo principalmente ético-político, en el juicio de gusto kantiano éstos (junto a su validez ejemplar) poseerían, por el momento, un valor por sí mismos, independientemente del contenido temático que alberguen, ya sean juicios puros o no puros. Ello significaría que en la experiencia estética los ejemplos no se anularían como instrumentos persuasivos, una vez alcanzado algún fin determinado. Si pudiera hablarse de la significatividad de los ejemplos estéticos, ésta tendría que ver con su simple presencia, que es capaz de promover un libre juego entre las facultades de conocimiento, vale decir, la belleza misma. Así las cosas, la "ejemplaridad del ejemplo" radicaría en que éste genera el convencimiento de que dicho juego no es un asunto privado, sino universal y necesario.

Así, al reforzarse la experiencia estética en su propia manifestación sensible, el carácter discursivo que la retórica otorga a los paredeigmas, permite una consideración más bien estético-intuitivo de la naturaleza de la ejemplaridad kantiana. Ahora bien, estético-intuitivo quiere decir que su representación sensible (la imagen), no solo gusta puntualmente; también posee la "fuerza persuasiva" suficiente para reclamar continuidad con el sentimiento de todos los demás sujetos. Y es que las imágenes estéticas en Kant (tanto lo bello como lo sublime), también refieren una relación entre lo general y lo particular que, al igual que los ejemplos, no permite ser tematizada conceptualmente. ${ }^{22}$

\footnotetext{
${ }^{21}$ Otra de las pruebas de persuasión, señala Aristóteles, la constituyen aquéllas en las que "<se persuade por disposición> de los oyentes, cuando éstos son movidos a una pasión por medio del discurso." (Rhet. 1356a 10-15). También resulta significativo recordar aquí que, según Kant, que en una crítica del gusto concebida como arte, importa tener presente, "las reglas fisiológicas (aquí, psicológicas) y, por tanto, empíricas, según las cuales el gusto, en realidad, procede.” (CJ\$34 B144-145).

${ }^{22}$ El paralelismo entre los ejemplos y las imágenes podría enfatizarse aún más, si se atiende la teoría kantiana que concibe la labor de la imaginación en los juicios estéticos y su configuración de imágenes, como un esquematizar sin concepto. (CJ\$35 B146).
} 
En este momento de la argumentación parece ya logrado otro de los objetivos del presente trabajo: una aproximación retórica alrededor de la noción de validez ejemplar desarrollada por Kant en su Crítica del juicio, que haría mucho más comprensible y plausible el tipo de normatividad allí involucrada. Como consecuencia de ello se ha logrado demostrar cómo, efectivamente, el ejemplo posee en palabras de Ferrara, una fuerza o atracción que lo hacen convincente y decisivo, es decir, persuasivo (FERRARA, 2008, p. 20). Y sin embargo, su fuerza persuasiva no procede del poder demostrativo de una ley o norma universal; más bien se trata de una universalidad, siguiendo a Ferrara, sin principios. Es decir, se trata de una validez autorreferencial, o en palabras de Kant, en el juicio gusto, éste es “objeto al par que ley” ( $C J \$ 36$ B148-49). Planteada de este modo, la fuerza del ejemplo manifiesta otra de las características que Ferrara le atribuye: esa fusión no forzada entre la realidad y la normatividad (o entre los hechos y las normas). En definitiva, al intentar cotejar la exposición kantianas del juicio estético con la retórica aristotélica, la propuesta de recuperar la noción de validez ejemplar, según Ferrara, para afrontar ciertos problemas mucho más sustanciales del presente filosófico, nos indica que tal forma de la normatividad bien puede trascender el terreno de lo estético. Esto significaría que no sería necesario violentar el todo de la estética filosófica kantiana, el proponer la noción de juicio reflexionante (y el de validez ejemplar o sentido común que le son consustanciales), como una plataforma normativa que, sin violentar el pluralismo, mantenga unas pretensiones universalistas y consensuales, tal cual lo plantea de Ferrara.

CASTRO HERNÁNDEZ, J. C. Exemplary validity, common sense, and universalism: a study of exemplarity in Kant and Aristotelian rhetoric. Trans/form/ação, Marília, v. 42, n. 3, p. 33-54, Jul./Set., 2019.

\footnotetext{
ABSTRACT: One of the most controversial notions in contemporary interpretations of the Critique of judgment is that of common sense. Along with it, Kant proposed a new model of normative validity called exemplary, whose approach is quite problematic. This article proposes a reading and an interpretation of this type of validity, based on the reinterpretation carried out by Alessandro Ferrara and from the point of view of the rhetorical tradition as represented by Aristotle. It intends to achieve an improved understanding of the problem in question and, at the same time, to make much more understandable the possibilities that Alessandro Ferrara attributes to this form of normativity.
}

KeYwords: Common sense. Rhetoric. Universalism. Aesthetic judgment. Exemplary validity. 


\section{REFERENCIAS}

ARENDT, H. Conferencias sobre la filosofía politica de Kant. Madrid: Paidós Ibérica, 2003.

ARISTÓTELES. Tratados de lógica (Órganon). Tradução de Miguel Candel Sanmartín. Madrid: Gredos, 1982.

. La Retórica. Tradução de Quintín Racionero. Madrid: Gredos, 1998.

BEINER, R. Introducción: conferencias sobre la filosofía política de Kant. Madrid: Paidós Ibérica, 2003.

BEINER, R; NEDELSKY, J. Judment, imagination, and politics. Themes from Kant and Arendt. Chicago: Rowman \& Littlefield, 2008.

CARRILLO, L. ¿Por qué para Kant la crítica de la facultad estética es la propedéutica de toda filosofía? Ideas y Valores, n. 110, p. 99-126, 1999.

DANTO, A. C. El abuso de la belleza: la estética y el concepto de arte. Buenos Aires: Paidós, 2005.

_L La transfiguración del lugar común: una filosofía del arte. Madrid: Paidós Ibérica, 2007.

DE SOUZA SANTOS, B. Crítica de la razón indolente: contra el desperdicio de la experiencia. Bilbao: Desclée De Brouwer, 2005. V. 1.

FERRARA, A. Autenticidad reflexiva. Madrid: La Balsa de la Medusa, 2002.

2008. . La fuerza del ejemplo: exploraciones del paradigma del juicio. Barcelona: Gedisa,

GADAMER, H. G. Verdad y método. Salamanca: Sígueme, 1990.

. El giro hermenéutico. Madrid: Cátedra, 2001.

. Estética y hermenéutica. Madrid: Tecnos, 2004.

GRASSI, E. Vico y el humanismo: ensayos sobre Vico, Heidegger y la retórica. Barcelona: Anthropos, 1992.

- El poder de la fantasía: observaciones sobre la historia del pensamiento universal. Barcelona: Anthropos, 2003.

JAUSS, H. R. Pequeña apología de la experiencia estética. Barcelona: Paidós, 2002.

KANT, E. Crítica de la facultad de juzgar. Traduccion Manuel García Morente. México: Porrúa, 1991. 1999.

. Critica de la facultad de juzgar. Traduccion Pablo Oyarzún. Caracas: Monte Ávila, . Antropología en sentido pragmático. Buenos Aires: Losada, 2009. 
PARRET, H. La teoría kantiana del afecto y la tonalidad afectiva del texto kantiano. In: SOBREVILLA, D. (ed.). Filosofía, política y estética en la crítica del juicio de Kant: actas del coloquio de Lima conmemorativo del bicentenario de la tercera critica. Lima: Universidad de San Marcos, 1991. p. 95-96.

PERELMAN, C.; OLBRECHS-TYTECA, L. Tratado de la argumentación: la nueva retórica. Madrid: Gredos, 2008.

QUINTANA, L. Gusto y comunicabilidad en la estética de Kant. Bogotá: Universidad Nacional de Colombia y Universidad de los Andes, 2008.

RACIONERO, Q. Introducción. In: ARISTÓTELES. La retórica. Traduccion. Quintín Racionero Madrid: Gredos, 1998.

VARGAS, G.; CÁRDENAS, L. G. Retórica, poética y formación: de las pasiones al entinema. Bogotá: Universidad de Antioquia y Universidad Pedagógica Nacional, 2005.

VICO, G. Obras: oraciones inaugurales y La antiquísima sabiduría de los italianos. Barcelona: Península, 2002. . Obras: Retórica (Instituciones de Oratoria). Barcelona: Península, 2004. 